\title{
Genetic Services and Attitudes in Primary Care Pediatrics
}

\author{
Michael L. Rinke, ${ }^{1 *}$ Natalie Mikat-Stevens, ${ }^{2}$ Robert Saul, ${ }^{3}$ Amy Driscoll, ${ }^{4}$ Jill Healy, ${ }^{2}$ and \\ Beth A. Tarini ${ }^{5}$
}

${ }^{1}$ Department of Pediatrics, Children's Hospital at Montefiore, Bronx, New York

${ }^{2}$ American Academy of Pediatrics, Elk Grove Village, Illinois

${ }^{3}$ Greenville Health System, Children's Hospital, Greenville, South Carolina

${ }^{4}$ Peakview Pediatrics, University of Colorado Health, Greely, Colorado

${ }^{5}$ Department of Pediatrics and Communicable Diseases, Child Health Evaluation and Research (CHEAR), University of Michigan, Ann Arbor, Michigan

Manuscript Received: 29 March 2013; Manuscript Accepted: 4 October 2013

Given the integral role primary care pediatricians (PCPs) play in caring for children with genetic conditions, we aimed to identify current practices of PCPs regarding genetic patients, their attitudes toward genetic medical care and their choices regarding family history taking. We conducted an on-line survey of a national convenience sample of PCPs associated with the American Academy of Pediatrics' Quality Improvement Innovation Networks. Eighty-eight respondents (29\% response rate) were included in the analysis. Seventy-four $(86 \%)$ reported ordering genetic based tests three or less times annually. Eleven (13\%) strongly agreed that they discuss with patients the potential risks, benefits, and limitations of genetic tests. Forty-three (49\%) agreed or strongly agreed that they feel competent in providing healthcare to patients related to genetics and genomics. Perceived competence was not associated with more recent training $(P=0.29)$, number of genetic tests ordered annually $(P=0.84)$ or mean number of weekly patient encounters $(P=0.15) .100 \%$ of participants stated that taking a family history is important. $27(31 \%)$ agreed or strongly agreed that they gather a minimum of a three-generation family history. Forty-one of the 63 participants with an electronic health record $(65 \%)$ reported their system was fair or poor in its ability to easily capture a three-generation family history. PCPs interested in quality improvement reported variation in care practices for children with genetic diseases and a majority did not feel competent to provide genetic related healthcare. Research should focus on improving the care and diagnosis of children with genetic disorders and enhanced integration of genetic medicine into routine primary preventative care. (c) 2013 Wiley Periodicals, Inc.

Key words: genetics; pediatrics; primary care; family history; electronic health record

\section{INTRODUCTION}

Pediatricians are often at the forefront of diagnosing and managing the care of patients with genetic disorders [Kemper et al., 2006].
How to Cite this Article:

Rinke ML, Mikat-Stevens N, Saul R, Driscoll A, Healy J, Tarini BA. 2014. Genetic services and attitudes in primary care pediatrics.

Am J Med Genet Part A 164A:449-455.

Early assessment, identification and intervention for genetic diseases lead to improved outcomes across a wide variety of pediatric and adult illnesses [Committee on Genetics, 2000; Department of Health, 2003; Yoon et al., 2003; Silversides, 2007]. Unfortunately, more than half of pediatricians would prefer newborn screening programs to manage the diagnostic work-up of positive newborn screens [Kemper et al., 2006], and only 39\% of pediatricians surveyed reported feeling competent to discuss Fragile X Syndrome screening, a relatively common genetic disorder, with families [Kemper and Bailey, 2009]. While general practitioners recognize their role in genetic diagnosis and management [Emery et al., 1999; Trinidad et al., 2008; McCahon et al., 2009; Houwink et al., 2011], they cite a number of obstacles to the accurate and timely identification of pediatric patients with genetic diseases [Committee on Genetics, 2000; Greendale and Pyeritz, 2001; Department of Health, 2003; Trinidad et al., 2008], including inadequate time, education, and genetic-focused resources [Suther and Goodson, 2003; Trotter and Martin, 2007; Houwink et al., 2011]. Furthermore, although

No authors have any conflicts of interest to disclose.

${ }^{*}$ Correspondence to:

Michael L. Rinke, M.D., Ph.D., Department of Pediatrics, Children's Hospital at Montefiore, 3415 Bainbridge Avenue, Bronx, NY 10467.

E-mail: mrinke@montefiore.org

Article first published online in Wiley Online Library

(wileyonlinelibrary.com): 19 November 2013

DOI 10.1002/ajmg.a.36339 
family history taking remains a cornerstone of any patient history and should be at the forefront when considering genetic diagnoses, significant gaps remain in primary care physicians' abilities, practices, and availability to conduct complete genetic family histories [Cole Johnson et al., 2004; Guttmacher et al., 2004; Trotter and Martin, 2007; Pyeritz, 2012].

As scientific advances such as the Human Genome Project and advanced molecular genetic testing promise improved abilities to diagnose and treat genetic conditions [Committee on Genetics, 2000], and families increasingly expect high-quality genetic developments to impact their medical care [Henneman et al., 2004], it is essential to understand the current practices, beliefs and knowledge of primary care pediatricians with regards to genetics. This study aims to identify: 1) current practices of primary care pediatricians regarding genetic patients, 2) their attitudes toward genetic medical care, and 3) their choices regarding family history taking, an essential tool in primary care and genetic diagnosis [Cole Johnson et al., 2004; Guttmacher et al., 2004; Trotter and Martin, 2007; Pyeritz, 2012]. Additionally, previous studies have suggested more recent medical training is associated with increased comfort with genetic medical care [McCahon et al., 2009], and our study aims to test this association. Primary care pediatricians (PCPs) are understudied with regards to their practices and beliefs regarding genetic patients and this study will help fill that knowledge gap. Data from this national survey will serve as a needs assessment for future projects aimed at improving the diagnosis and management of genetic disorders in pediatric primary care.

\section{MATERIALS AND METHODS}

\section{Survey Design and Administration}

An expert panel, comprised of genetic experts, PCPs and quality improvement specialists, was convened through the American Academy of Pediatrics' (AAP) Genetics in Primary Care Institute (GPCI). The GPCI- a cooperative agreement between the AAP and the Health Resources Services Administration Maternal and Child Health Bureau - was created to increase the use of genetic medicine among primary care providers. The AAP's Quality Improvement Innovation Networks (QuIIN) - a program of the AAP which is home to multiple pediatric quality improvement networks designed to improve care for children and their families in both the inpatient and outpatient settings-became involved with the GPCI to test and identify strategies to improve delivery of pediatric genetic services and the care and management of pediatric patients with defined genetic conditions. As a first step, the group developed a survey to identify needs and current practices of PCPs regarding genetics, genetic evaluations, and genetic patients.

The survey was modeled on a survey used by researchers at the University of Michigan to understand how adult and pediatric practitioners interact with genetics patients, and personal communication with staff involved in a genetics education project at El Camino Hospital Genomic Medical Institute (unpublished data). The survey was pilot tested with eight PCP members of the expert panel and revised as needed using expert consensus and literature review. The final survey contained 43 questions, was administered on-line, and asked about PCP demographics, current practices regarding genetics, attitudes toward genetics in primary care and family history practices. Specific questions included access and referral to genetic specialists, comfort with and frequency of genetic testing, electronic health record utility for family history taking and familiarity with genetic resources. Most questions were constructed on a four-point Likert scale in order to force participants to select a negative or positive position [Chang, 1994]. Frequency or perceived quality questions were constructed on a five-point Likert scale. The complete survey can be viewed in the Supplementary Section.

A convenience sample of the QuIIN email listserv, which included 300 practicing PCPs interested in quality improvement science, was used in this study. These PCPs are "early adopters" who are interested in improving their care practices and may be biased toward better compliance with national recommendations and more motivated to care for patients with rare disease states. A reminder email was sent after one week and participants received a 20-dollar inducement for participation. The survey was conducted in February, 2012 and was approved by the AAP Institutional Review Board.

\section{Statistical Analyses}

Descriptive statistics including mean, standard deviation, median and Interquartile Range (IQR) were used to summarize the survey responses. As participants were able to skip questions, the total number of participants varied for each question. Mann-Whitney two-sample statistics were used to test associations between feeling competent in providing healthcare to patients related to genetics and genomics (strongly agree and agree vs. strongly disagree and disagree) and the non-parametric variables of 1) year participants finished residency and 2) number of genetic tests ordered annually. Fischer's exact test was used to test the hypothesis that PCPs seeing more patients per week were more likely to refer more patients to geneticists, send more genetics tests or feel competent in providing healthcare to patients related to genetics and genomics. This hypothesis was generated from a previous study [Kemper et al., 2006] indicating pediatricians were more likely to believe they should be responsible for arranging confirmatory genetic testing and subspecialty genetic evaluation than family practitioners, who presumably see less pediatric patients per week. Fisher's exact test was also used to test the association between providers who feel competent in providing healthcare to patients related to genetics and genomics (strongly agree and agree vs. strongly disagree and disagree) and completing a three-generation family history.

\section{RESULTS}

\section{Demographics}

Eighty-nine PCPs on the QuIIN email listserv participated in the study. One participant was excluded because their current practice was outside of the United States, resulting in 88 total participants (29\% response rate). Demographics for respondents are presented in Table I. Participants practiced in 32 states and Puerto Rico, were $65 \%$ female and $97 \%$ medical doctors, and they came from varying practice settings and mean patient volumes. The median year participants finished residency was 1990 (IQR 1982, 2002). 


\section{TABLE I. Participant Demographics}

\section{Characteristic}

Gender: Female

Age: median (IQR)

Year finished residency: median (IQR)

Degree

Medical Doctorate

Doctor of osteopathy

Nurse practitioner

Practice setting

Urban, inner city

Urban, not inner city

Suburban

Rural

Patient encounters per week

$0-40$

$41-60$

$61-80$

$81-100$

101-120

Greater than 120

Practice description

Pediatric group: 1 or 2 physicians

Pediatric group: 3-10 physicians

Pediatric group: $>10$ physicians

Multispecialty group

Health maintenance organization

Medical school or university

Non-government hospital

Non-profit community healthcenter

Government hospital or clinic

Respondents were able to skip questions so total $\mathrm{N}$ is less than 88 for some questions.
Number $[\%], \mathbf{N}=\mathbf{8 8}^{\mathrm{a}}$ 55 (65)

$52.5(41,62)$

1990 [1982, 2002]

82 (97)

2 (2)

$1(1)$

19 (22)

23 (27)

$30(35)$

$13(15)$

16 (19)

8 (9)

13 (15)

$15(18)$

$18(21)$

15 (18)

12 (14)

$30(34)$

8 (9)

11 (13)

3 (3)

9 (10)

4 (5)

3 (3)

8 (9)

\section{Provision of Genetics Services}

Excluding newborn screening, 74 participants (86\%) report ordering genetic based tests zero to three times annually and ordering more genetic based tests was not associated with the mean number of PCP patient encounters per week $(P=0.64)$. Annually, participants ordered an average of 1.5 biochemical tests (median one), 1.9 DNA-based microarray tests (median zero), 1.8 DNA-based tests for specific disorders (median zero) and 2.7 karyotype tests (median two). Eleven participants (13\%) strongly agreed and 49 (57\%) agreed that they discuss with patients the potential risks, benefits, and limitations of the test in question.

Participants referred a mean of 4.8 patients per year to a geneticist and there was no association between the mean number of PCP patient encounters per week and the number of patients referred to a geneticist $(P=0.51)$. Seventy-two respondents $(83 \%)$ indicated that their practice has a system in place to refer patients to genetics professionals. Seventy-seven respondents (89\%) reported having access to a trusted genetics professional and $65(75 \%)$ reported their genetic professionals are less than or equal to 30 miles from their practice.

\section{Attitudes Toward Genetics Services}

One-hundred percent of respondents agreed or strongly agreed that genetic evaluations are useful for their patients. Of 86 respondents, $90 \%$ reported knowing when to refer to a genetic professional, $88 \%$ believed they are able to effectively explain the reasons and benefits of genetics services, $74 \%$ reported understanding their role in providing genetic services and $76 \%$ reported understanding their role in providing follow-up for genetic services. Reasons for referral to a geneticist cited as very important by a majority of participants included desire for management recommendation (51 participants, $59 \%$ ), severity of disorder (48 participants, 57\%), complexity of disorder (47 participants, 55\%) and parental desire for more information (44 participants, 51\%). The reason for referral to a geneticist cited as not important by a majority of participants was malpractice concerns (45 participants, 53\%; Table II).

Forty-three participants (49\%) agreed or strongly agreed that they feel competent in providing healthcare to patients related to genetics and genomics. Participants who agreed or strongly agreed did not complete residency more recently than participants who

\section{TABLE II. Factors in Pediatrician's Decision to Refer a Child for a Genetics Consultation}

Complexity of disorder

Severity of disorder

Familiarity with the condition

Desire for management recommendation

Insurance coverage of consultation

Known treatment available

Malpractice concerns

Parental desire for more information

Parental interest in the referral

Other
Not important

\section{$\mathbf{N}^{\mathbf{a}}$}

86

85

86

86

85

86

85

86

86

10

\section{[\%]}

$1(1.2)$

$-$

7 (8.1) $-$

$15(18)$

13 (15)

45 (53)

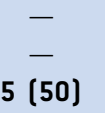

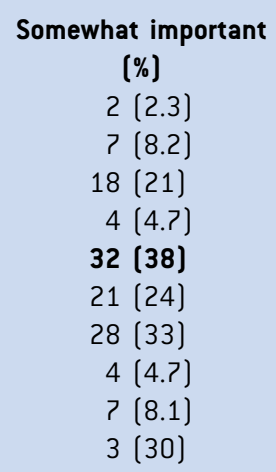

$\begin{gathered}\text { Important } \\ {[\%]}\end{gathered}$
$35[41]$
$29[34)$
$31[36]$
$31(36)$
$25[29]$
$37[43]$
$8(9.4)$
$37(43)$
$40[47]$
$2(20)$

Very important
$[\%]$
$\mathbf{4 8}[56]$
$\mathbf{4 9}[58]$
$30[35]$
$\mathbf{5 1}[59]$
$13[15]$
$15[18]$
$4[4.7]$
$\mathbf{4 5}[52]$
$39[45]$
-

Most frequent answer is bolded.

${ }^{a}$ Respondents were able to skip questions so total $\mathrm{N}$ is less than 88 for some questions.

${ }^{\mathrm{b}}$ Responses were coded as $1-4$, with very important equal to 4 . 
disagreed or strongly disagreed (median residency completion year 1992.5 vs.1987.5; $P=0.29$ ). Similarly, there was no association between the number of genetic tests ordered by providers annually or the mean number of PCP patient encounters per week and a feeling of competence in providing healthcare to patients related to genetics and genomics ( $P=0.84$ and $P=0.15$, respectively).

Sixty-six participants (76\%) agreed or strongly agreed that they understand the role of genetics in the onset of disease and 58 (67\%) reported understanding the role of genetics in patients' response to treatments. Sixty-six respondents (77\%) agreed or strongly agreed that they are comfortable with ordering chromosomal tests, 33 (39\%) are comfortable ordering DNA tests and 29 (34\%) are comfortable ordering metabolic tests, but only 35 participants (41\%) reported having adequate resources to determine the appropriate test to order. Fifty-one participants (59\%) reported they understand the ethical, legal, and social issues related to genetic testing and recording of genetic information. When presented with a list of 12 national genetics resources for genetic specific information or services, 17 respondents (19\%) reported that they were unfamiliar with all of the resources and 20 additional respondents (23\%) reported that they were only familiar with one of the resources.

When asked what would incentivize their practice to more effectively integrate genetic-based medicine into primary care, 80 participants (94\%) cited increased understanding of genetics, 75 $(88 \%)$ cited continuing medical education opportunities related to genetics, 70 (85\%) cited improved reimbursement, 70 (83\%) cited providing a more comprehensive medical home, 66 (79\%) cited increased relevance of genetics to primary care, and 59 (69\%) cited easier access to genetic professionals.

\section{Family History Practices}

One-hundred percent of participants agreed or strongly agreed that "taking a family history is an important part of the assessment of an individual's predisposition to disease." Twenty-seven respondents (31\%) agreed or strongly agreed that they gather a minimum of a three-generation family health history for all of their patients and this was not associated with a feeling of competence in providing healthcare to patients related to genetics and genomics $(P=0.25)$. Ninety-eight percent of participants agreed or strongly agreed that collecting a three-generation family health history is impeded by patients unable to provide accurate/complete information (Table III). Of the 63 participants who reported having an electronic health record, 41 (65\%) reported their electronic health system was fair or poor in its ability to easily and efficiently capture genetics information and a three-generation family history.

Thirty-six participants (41\%) reported that they administer a standardized checklist of diseases to aid in obtaining a family history. When obtaining a family history, 45 participants (51\%) ask general questions about diseases that run in the family and about the health of specific family members, 27 (31\%) only ask general questions about diseases that run in the family, 11 (12\%) only ask about the health of specific family members, four (4\%) ask no questions and only administer a standardized checklist of diseases,

TABLE III. Attitudes and Practices in Family History Taking by Primary Care Pediatricians

\begin{tabular}{|c|c|c|c|c|c|c|c|c|}
\hline Question & $\mathrm{N}^{\mathrm{a}}$ & $\begin{array}{c}\text { Strongly } \\
\text { disagree } \\
{[\%]}\end{array}$ & \multicolumn{2}{|c|}{$\begin{array}{l}\text { Disagree } \\
{[\%]}\end{array}$} & $\begin{array}{l}\text { Agree } \\
{[\%]}\end{array}$ & $\begin{array}{c}\text { Strongly agree } \\
{[\%]}\end{array}$ & \multicolumn{2}{|l|}{$\begin{array}{l}\text { Mean } \\
\text { rating }\end{array}$} \\
\hline $\begin{array}{l}\text { Taking a family health history is an important } \\
\text { part of the assessment of an individual's [or } \\
\text { patient's] predisposition to disease }\end{array}$ & 87 & - & \multicolumn{2}{|c|}{-} & $30(34)$ & $57[66]$ & \multicolumn{2}{|l|}{3.66} \\
\hline $\begin{array}{l}\text { I gather a minimum of a three generation family } \\
\text { health history information for all of my } \\
\text { patients }\end{array}$ & 86 & $9(10)$ & \multicolumn{2}{|c|}{$50[58]$} & $17(20)$ & 10 (12) & \multicolumn{2}{|l|}{2.34} \\
\hline $\begin{array}{l}\text { When collecting a three generation family } \\
\text { history, a barrier that I face is that patients } \\
\text { are unable to provide accurate/complete } \\
\text { information }\end{array}$ & 87 & - & \multicolumn{2}{|c|}{$2(2)$} & 51 [59] & 34 (39) & \multicolumn{2}{|l|}{3.36} \\
\hline Question & & $\mathbf{N}$ & $\begin{array}{c}\text { Never } \\
{[\%]}\end{array}$ & $\begin{array}{c}\text { Rarely } \\
{[\%]}\end{array}$ & $\begin{array}{l}\text { Some of } \\
\text { the time } \\
{[\%]}\end{array}$ & $\begin{array}{l}\text { Most of } \\
\text { the time } \\
{[\%]}\end{array}$ & $\begin{array}{c}\text { Always } \\
{[\%]}\end{array}$ & $\begin{array}{c}\text { Mean } \\
\text { rating }^{\mathrm{b}}\end{array}$ \\
\hline \multicolumn{9}{|c|}{$\begin{array}{l}\text { For each of the following visit types, how often do you obtain } \\
\text { or update a family health history for a patient? }\end{array}$} \\
\hline \multicolumn{2}{|l|}{ At first visit (either acute or health maintenance) } & 87 & - & $1(1)$ & $10(12)$ & 33 (38) & 43 [49] & 1.64 \\
\hline \multicolumn{2}{|l|}{ At health maintenance visits } & 87 & $1(1)$ & $7(8)$ & $30(35)$ & $35[40]$ & $14(16)$ & 2.39 \\
\hline \multicolumn{2}{|l|}{ When a specific health problem arises } & 85 & - & $4(5)$ & 25 (29) & 33 [39] & 23 (27) & 2.11 \\
\hline \multicolumn{2}{|c|}{$\begin{array}{l}\text { How often do you construct a pedigree (eg, diagram of family } \\
\text { members' relationships] with this information? }\end{array}$} & 86 & 30 (35) & $44[51]$ & $8(10)$ & $2(2)$ & $2(2)$ & 1.89 \\
\hline
\end{tabular}


and one (1\%) reported not usually obtaining a family history. While 76 participants $(87 \%)$ reported always or most of the time collecting a family history at the first visit, only 49 (56\%) reported always or most of the time updating the family history at health maintenance visits and only 56 (66\%) reported always or most of the time updating the family history when a specific health problem arises. Only four participants (5\%) reported constructing a pedigree with information from the family health history "always" or "most of the time" (Table III).

Appreciable variation existed between providers and the information they collect in the family history. Nearly all reported collecting information from relatives in the direct line of descent: 82 participants (93\%) inquire about siblings and parents when collecting a family health history and 79 (90\%) inquire about grandparents. Fewer collect information about more distantly related relatives: 47 (53\%) inquire about aunts and uncles, 25 (28\%) inquire about cousins, and 19 (22\%) inquire about nieces and nephews. As for the type of information that providers collect, 61 respondents $(69 \%)$ inquire about the cause and age of death of family members, 54 respondents $(61 \%)$ inquire about the age of onset of medical conditions and $50(57 \%)$ inquire about the gender of family members. Only 28 (32\%) inquire about ages of family members, $15(17 \%)$ inquire about ethnic background of family members, and 7 (8\%) inquire about consanguinity.

\section{DISCUSSION}

This national survey of PCPs actively involved in quality improvement activities identified significant areas of improvement for the diagnosis and care of pediatric genetic patients in the primary care setting. The majority of PCPs order zero to three genetic tests and refer five or fewer patients to a geneticist annually, and only $49 \%$ agree or strongly agree that they feel competent in providing healthcare to patients related to genetics and genomics. It is unclear if PCPs order few tests because they feel incompetent or if they feel incompetent and therefore order few tests. Prior studies have identified deficiencies in PCP genetic medical knowledge which could be driving PCP perceived incompetence [Kolb et al., 1999; Suther and Goodson, 2003; Kemper and Bailey, 2009], and importantly, can be rectified with intensive, focused training on genetic topics [Kolb et al., 1999]. This perceived incompetence is more concerning as one-quarter of participants had to refer patients to a geneticist greater than 30 miles from their practice, suggesting long travel times for patients, increased potential for non-compliance with visits and decreased likelihood of PCP referral to geneticists [Chen et al., 2008]. Although gathering a comprehensive family history has been identified as integral to the care and diagnosis of genetic patients [Guttmacher et al., 2004; Pyeritz, 2012] and all participants indicated it is an important part of the assessment of an individual's predisposition to disease, less than one-third of participants gather a minimum of a three generation family health history for all of their patients. Moreover, large variations exist in the methods used and data collected for family history. As 65\% of participants reported their electronic health system was fair or poor in its ability to easily and efficiently capture genetics information and a three-generation family history, many electronic health records are not meeting "meaningful use" standards with regards to genetics [Blumenthal and Tavenner, 2010].
Similar to previous studies of general practitioners [Suchard et al., 1999; Greendale and Pyeritz, 2001; McCahon et al., 2009], our findings demonstrate the majority of PCPs do not feel comfortable providing care to patients related to genetics. The findings did not indicate, however, that comfort with genetic medical care was associated with years since residency, number of genetic tests ordered annually [McCahon et al., 2009] or number of patients seen. Furthermore, even PCPs who reported feeling competent in caring for patients with genetics diseases, are not consistently taking three-generation family histories. This suggests that all PCPs, not just ones who are distant from residency training, have low patient volumes or have self-reported low competence in caring for genetic patients, need increased access to education and increased resources aimed at caring for patients with genetic diseases.

Our data suggest a number of potential avenues to improve care and diagnosis of genetic patients, including continuing medical education, increased reimbursement for genetic services and easier access to genetic professionals. Fifty-nine percent of participants reported not having adequate resources to determine the appropriate genetic test to order and $42 \%$ were aware of one or zero national resources regarding genetic information or services. Leveraging and publicizing these existing resources could lead more PCPs to understand the importance of genetic testing and diagnoses, and decrease the $30 \%$ of PCPs who do not routinely discuss the potential risks, benefits, and limitations of genetic tests with patients. Emphasizing the legal risks and implications of missing genetic diagnoses or recurrent births with a genetic disorder [Shapira, 1998; Roth, 2007], may not improve care of genetic patients as a majority of PCPs felt malpractice concerns were not important in their decision to refer to a geneticist.

Collecting a family history is considered a standard part of the medical examination [Guttmacher et al., 2004; Trotter and Martin, 2007; Orlando et al., 2011] and family history clearly predicts risk for a number of pediatric and adult diseases [Harrison et al., 2003; Cole Johnson et al., 2004]. Despite previous studies showing improved patient identification of serious disease states by standardizing family history practices [O’Neill et al., 2009; Cohn et al., 2010; Qureshi et al., 2012], providers in this study reported poor compliance with taking three-generation family histories and large variations in information collected during the family history, including only $8 \%$ of providers asking about consanguinity. This finding supports previous research [Suchard et al., 1999; Trotter and Martin, 2007; Bishop et al., 2008; Kemper and Bailey, 2009], and points to a persistent need for intervention to improve family health history taking and breaking down potential consanguinity taboos [Bishop et al., 2008], even in physicians who self-report feeling competent in caring for genetics patients [Guttmacher et al., 2004; Pyeritz, 2012]. While previous studies suggest computer systems can improve family history taking [Acheson et al., 2006; O'Neill et al., 2009; Cohn et al., 2010; Orlando et al., 2011], PCPs in our study reported dissatisfaction with their electronic health records' abilities to collect and facilitate a three-generation family history. In the era of genomic medicine, the family history is more important than ever [Guttmacher et al., 2004; Pyeritz, 2012] and rapid electronic and non-electronic solutions are needed to improve a PCP's ability to collect and interpret vital family history data. For example, family history tools that flag concerning responses and suggest 
potential action steps for PCPs via clinical decision support would be invaluable tools for future study [Wu et al., 2013].

This national survey contains limitations. We utilized a convenience sample of PCPs associated with QuIIN, who are self-selected for their interest in quality improvement science. These individuals may not be representative of all PCPs nationally and may be biased toward better compliance with national recommendations and more motivated to care for patients with rare disease states. Our response rate was $29 \%$ and we acknowledge the potential for nonresponse bias and are unable to report on how it could have affected our results [Johnson and Wislar, 2012]. Both of these factors potentially limit the generalizability of our findings. Even though our survey was based on previous surveys focused on general practitioner attitudes toward genetics and the survey was piloted, it has not been validated. Social desirability bias is also possible and could have skewed our results toward higher rates of agreement with questions.

In conclusion, a national sample of PCPs interested in quality improvement science reported a mean genetic patient referral rate of less than five patients annually, $86 \%$ ordered genetic based tests zero to three times annually, wide variability in care practices and expressed discomfort with genetic testing and caring for children with genetic diseases. Given the ubiquitous nature of genetic conditions and the potentially life threatening outcomes of these diagnoses, it is imperative that future research focus on improving the care and diagnosis of children with geneticsrelated conditions through education and rigorous quality improvement work.

\section{REFERENCES}

Acheson LS, Zyzanski SJ, Stange KC, Deptowicz A, Wiesner GL. 2006. Validation of a self-administered, computerized tool for collecting and displaying the family history of cancer. J Clin Oncol 24:5395-5402.

Bishop M, Metcalfe S, Gaff C. 2008. The missing element: Consanguinity as a component of genetic risk assessment. Genet Med 10:612-620.

Blumenthal D, Tavenner M. 2010. The "meaningful use" regulation for electronic health records. N Engl J Med 363:501-504.

Chang L. 1994. A psychometric evaluation of 4-point and 6-point likerttype scales in relation to reliability and validity. Appl Psychol Meas 18:205-215.

Chen MJ, Holt CL, Lose EJ, Robin NH. 2008. The use by Alabama pediatricians of genetics consultation in the evaluation of developmental delay. Am J Med Genet Part A 146A:421-425.

Cohn WF, Ropka ME, Pelletier SL, Barrett JR, Kinzie MB, Harrison MB, Liu Z, Miesfeldt S, Tucker AL, Worrall BB, Gibson J, Mullins IM, Elward KS, Franko J, Guterbock TM, Knaus WA. 2010. Health Heritage(c) a webbased tool for the collection and assessment of family health history: Initial user experience and analytic validity. Public Health Genomics 13:477-491.

Cole Johnson C, Ownby DR, Havstad SL, Peterson EL. 2004. Family history, dust mite exposure in early childhood, and risk for pediatric atopy and asthma. J Allergy Clin Immunol 114:105-110.

Committee on Genetics. 2000. Molecular genetic testing in pediatric practice: A subject review. Pediatrics 106:1494-1497.

Department of Health. 2003. Our inheritance, our future realising the potential of genetics in the NHS. London: Crown copyright.
Emery J, Watson E, Rose P, Andermann A. 1999. A systematic review of the literature exploring the role of primary care in genetic services. Fam Pract 16:426-445.

Greendale K, Pyeritz RE. 2001. Empowering primary care health professionals in medical genetics: How soon? How fast? How far? Am J Med Genet 106:223-232.

Guttmacher AE, Collins FS, Carmona RH. 2004. The family history-More important than ever. N Engl J Med 351:2333-2336.

Harrison TA, Hindorff LA, Kim H, Wines RC, Bowen DJ, McGrath BB, Edwards KL. 2003. Family history of diabetes as a potential public health tool. Am J Prev Med 24:152-159.

Henneman L, Timmermans DR, van der Wal G. 2004. Public experiences, knowledge and expectations about medical genetics and the use of genetic information. Community Genet 7:33-43.

Houwink EJ, van Luijk SJ, Henneman L, van der Vleuten C, Jan Dinant G, Cornel MC. 2011. Genetic educational needs and the role of genetics in primary care: A focus group study with multiple perspectives. BMC Fam Pract 12:5.

Johnson TP, Wislar JS. 2012. Response rates and nonresponse errors in surveys. JAMA 307:1805-1806.

Kemper AR, Bailey DB Jr. 2009. Pediatricians' knowledge of and attitudes toward fragile $\mathrm{X}$ syndrome screening. Acad Pediatr 9: 114-117.

Kemper AR, Uren RL, Moseley KL, Clark SJ. 2006. Primary care physicians' attitudes regarding follow-up care for children with positive newborn screening results. Pediatrics 118:1836-1841.

Kolb SE, Aguilar MC, Dinenberg M, Kaye CI. 1999. Genetics education for primary care providers in community health settings. J Community Health 24:45-59.

McCahon D, Holder R, Metcalfe A, Clifford S, Gill P, Cole T, Sleightholme HV, Wilson S. 2009. General practitioners' attitudes to assessment of genetic risk of common disorders in routine primary care. Clin Genet 76:544-551.

O'Neill SM, Rubinstein WS, Wang C, Yoon PW, Acheson LS, Rothrock N, Starzyk EJ, Beaumont JL, Galliher JM, Ruffin MTt. 2009. Familial risk for common diseases in primary care: The Family Healthware Impact Trial. Am J Prev Med 36:506-514.

Orlando LA, Hauser ER, Christianson C, Powell KP, Buchanan AH, Chesnut B, Agbaje AB, Henrich VC, Ginsburg G. 2011. Protocol for implementation of family health history collection and decision support into primary care using a computerized family health history system. BMC Health Serv Res 11:264.

Pyeritz RE. 2012. The family history: The first genetic test, and still useful after all those years? Genet Med 14:3-9.

Qureshi N, Armstrong S, Dhiman P, Saukko P, Middlemass J, Evans PH, Kai J. 2012. Effect of adding systematic family history enquiry to cardiovascular disease risk assessment in primary care: A matchedpair, cluster randomized trial. Ann Intern Med 156:253-262.

Roth R. 2007. Congenital disabilities and the law. Clin Perinatol 34:263273, v-vi.

Shapira A. 1998. 'Wrongful life' lawsuits for faulty genetic counselling: Should the impaired newborn be entitled to sue? J Med Ethics 24:369375 .

Silversides A. 2007. The wide gap between genetic research and clinical needs. CMAJ 176:315-316.

Suchard MA, Yudkin P, Sinsheimer JS, Fowler GH. 1999. General practitioners' views on genetic screening for common diseases. Br J Gen Pract 49:45-46. 
Suther S, Goodson P. 2003. Barriers to the provision of genetic services by primary care physicians: A systematic review of the literature. Genet Med 5:70-76.

Trinidad SB, Fryer-Edwards K, Crest A, Kyler P, Lloyd-Puryear MA, Burke W. 2008. Educational needs in genetic medicine: Primary care perspectives. Community Genet 11:160-165.

Trotter TL, Martin HM. 2007. Family history in pediatric primary care. Pediatrics 120:S60-S65.
Wu RR, Orlando LA, Himmel TL, Buchanan AH, Powell KP, Hauser ER, Agbaje AB, Henrich VC, Ginsburg GS. 2013. Patient and primary care provider experience using a family health history collection, risk stratification, and clinical decision support tool: A type 2 hybrid controlled implementation-effectiveness trial. BMC Fam Pract 14:111.

Yoon PW, Scheuner MT, Khoury MJ. 2003. Research priorities for evaluating family history in the prevention of common chronic diseases. Am J Prev Med 24:128-135. 